\title{
Structural Properties of Zinc Aluminate $\mathrm{ZnAl}_{2} \mathrm{O}_{4}$ Compound
}

\author{
Hothama A. Mohammed \\ Raad A. Rasool \\ Department of Physics/College of Education for Pure Science/ University of Mosul
}

(Received 3 / 10/2018; Accepted 25 / 2 / 2019)

\begin{abstract}
Zinc Aluminate, $\mathrm{ZnAl}_{2} \mathrm{O}_{4}$ is prepared using the double sintering heating which is known as the ceramic method at high temperatures $1000 \mathrm{C}^{\mathrm{o}}$. The structural properties are studied using the $\mathrm{X}$-ray and Infrared techniques at room temperature. It was found that the compound has the spinel face centered cubic structure by showing the diffractions from the main crystalline planes of the spinel structured. The infrared spectrum shows the main absorption bands for the tetrahedral and octahedral sites. The lattice constant, " $a_{h k l}$ ", is calculated using Bragg's equation and found to be equal to $(8.0573 \AA)$. The force constants, the average crystallite size, densities and the porosity are calculated using the X-ray and Infrared results.
\end{abstract}

Keywords: Spinel structure, Sintering heating, X-ray, Infrared.

\section{الخصائص التركيبية لمركب ألومينات الخارصين ZnAl}

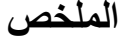

$$
\begin{aligned}
& \text { تم تحضير مركب ألومينات الخارصين بطريقة المعالجة الحرارية المزدوجة المعروفة بالطريقة السيراميكية عند درجات حرارية } \\
& \text { عالية 1000 Co } \\
& \text { الحمراء في درجة حرارة الغرفة. أوضحت نتائج الدراسة امتلاك المركب الناتج لتركيب السبينل المكعب متمركز الأوجه. حيث } \\
& \text { ظهرت انعكاسات المستويات البلورية الرئيسية في طيف حيود الأشعة السينية الدالة على هذا التركيب. كما ظهرت حزمتا }
\end{aligned}
$$

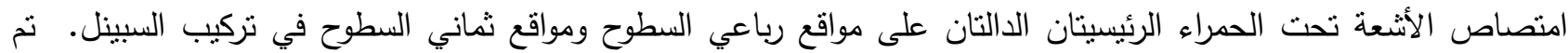

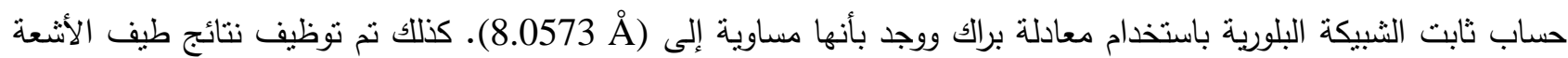

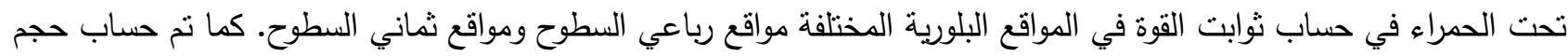

$$
\begin{aligned}
& \text { البلورات الصغيرة والكثافة النظرية والعملية وحساب المسامية. } \\
& \text { الكلمات الدالة: تركيب السبينل، المعالجة الحرارية، الأشعة السينية، الأشعة تحت الحمراء. }
\end{aligned}
$$

\section{INTRODUCTION}

Recent decades have witnessed a wide interest and very active search for spinel compounds (Ferrites, Aluminate and others). This is due to the fact that these materials have excellent synthetic, electrical and magnetic properties. They can be used in industrial applications such as permanent magnets, magnetic recording devices, electronics, communications and by Core transformers .... (Snelling, 1988) (Sugimoto, 1999).

Another advantage of this material is the ability to control these properties by changing the elements involved in the installation of these materials. The general chemical formula of these materials can be represented as $\mathrm{AB}_{2} \mathrm{X}_{4} \cdot\left(\mathrm{A}^{2+}=\mathrm{Co}, \mathrm{Ni}, \mathrm{Cu}, \mathrm{Mg}, \mathrm{Zn}, \ldots\right)$, while $\mathrm{B}$ represents a trivalent metal such as iron, nickel, chrome, aluminum, manganese and others $\left(\mathrm{B}^{3+}=\mathrm{Fe}, \mathrm{Cr}, \mathrm{Al}\right.$, 
$\mathrm{Ni}, \mathrm{Mn}, .$. ). And $\mathrm{X}$ is a bivalent metal, such as oxygen, sulfur, selenium, telium and others $\left(\mathrm{O}^{2-}=0, \mathrm{~S}, \mathrm{Se}, \mathrm{Te}, \ldots\right)$.

The normal spinel cell unit contains 32 Oxygen ions $\mathrm{O}^{2-}$ in a face center cubic lattice. Oxygen spike penetrated by 32 cations in octahedral locations and there are 64 sites in tetrahedral locations. While 1/8 binary sites occupied tetrahedral positions, and the trivalent cations occupied $1 / 2$ sites of the eight octagonal or octahedral positions (Snelling, 1988).

The compound under this study zinc aluminate $\mathrm{ZnAl}_{2} \mathrm{O}_{4}$ is found in nature and is known as Gahnite metal (Mineralogy Database, 2001-2005). This compound is one of the wide-band gap semiconductors which are used in metal and alloy reinforcement industry to provide durability against most reactions. It has also become technically important because of its optical properties, as it has an optical band gap equal to (3.8-3.9) eV, Making it very suitable in the hardware industry of photo-electronic devices operating in ultraviolet frequency range. It was also used in the manufacture of ceramics and electrodes due to its high mechanical and chemical properties (Martin, 2010). The electronic composition of this compound and the calculation of the energy gap of the spinel compounds were studied and found to be equal to $4.11 \mathrm{eV}$ (Sampath, 1999).

Most studies have shown that zinc ions prefer to be found in tetrahedral locations and that aluminum ions prefer to be present at eight surface locations. The distribution of different cations in different locations depends greatly on the conditions such as methods of heat treatment, temperature, duration of heating, concentration of these cations and others. It has been demonstrated practically and theoretically that the $\mathrm{ZnAl}_{2} \mathrm{O}_{4}$ compound favors natural spinel synthesis. The structure of this compound will be treated as a (Normal Spinel) structure. The divalent zinc ions occupy the four-brightness positions and the trigonometric aluminum ions act as the octagonal sites. This is supported by most studies on the composition of the substance (Hill, 1979) (Standley, 1962).

As this study using X-Ray Diffraction (XRD) and Infrared (IR) spectroscopy are important scientific research methods in investigating the structure properties of materials. Through using of $\mathrm{X}$-Ray Diffraction technology, the crystalline structure can be determined by calculating lattice constants of materials and by calculating the small size of this materials (Crystallites). Beside Infrared Absorption Technique clearly shows numbers and types of frequencies at which the absorption of the radiation occurs between the chemical bonds of atoms. By using these frequencies we can calculat force constants between ions with different chemical equivalents such as zinc, aluminum and oxygen ions in this compound.

\section{EXPERIMENTAL PART}

Zinc aluminate samples were prepared by using (Ceramic double sintering method). By taking the appropriate weights from the primary oxides of zinc oxide $\mathrm{ZnO}$ and aluminum oxide $\mathrm{Al}_{2} \mathrm{O}_{3}$ in the rate of 1:1 and then grinded and mixed ingredients well so as to increas the degree of homogeneity. The mixture then placed in a ceramic crucible in the furnace at $1000{ }^{\circ} \mathrm{C}$ for 24 hours and then gradually cooled to room temperature. Repeat the grinding and mixing process again. At this stage a quantity of material is taken and a disc is brought with a piston and under high pressure. This disc will be used later in calculating the practical density for comparison with the theoretical density and then calculating the porosity. The heating is returned at a relatively higher temperature of $1100{ }^{\circ} \mathrm{C}$ for 24 hours, Gradually cooled to room temperature. The chemical reaction between $\mathrm{ZnO}$ and aluminum oxide $\mathrm{Al}_{2} \mathrm{O}_{3}$ expected as following:

$$
\mathrm{ZnO}+(\gamma) \mathrm{Al}_{2} \mathrm{O}_{3} \Rightarrow \mathrm{ZnAl}_{2} \mathrm{O}_{4}
$$


Quantities of the resulting material are taken for the purpose of studying the (X-Ray diffraction) spectra and Infrared Spectrum. X-Ray sample was prepared by placing a quantity of powder on a glass slide placed in the X-Ray diffraction by type Phillips PW1820 diffract meter with ray source $\mathrm{CuK} \alpha$ and the wavelength $(\lambda=1.5404 \AA)$ in the range of angles $5^{\circ}$ to $70^{\circ}$. And by mixing a small amount of powder with a quantity of $\mathrm{KBr}$ powder and mix well and then be compressed into a disk with a thickness of up to $1 \mathrm{~mm}$ placed in infrared device type PERKIN-ELMER-1430.

\section{RESULTS AND DISCUSSION}

The X-Ray diffraction spectrum of $\mathrm{ZnAl}_{2} \mathrm{O}_{4}$ shown in Fig. (1), of the main reflections of the crystal levels known for spinel compounds in the range of reflection angles $\left(5^{\circ}-70^{\circ}\right)$. Table (1) illustrates these levels and reflection angles $2 \theta$, intensity, the value of crystal lattice, and the mid width reflection (Full width at half maximum, FWHM).

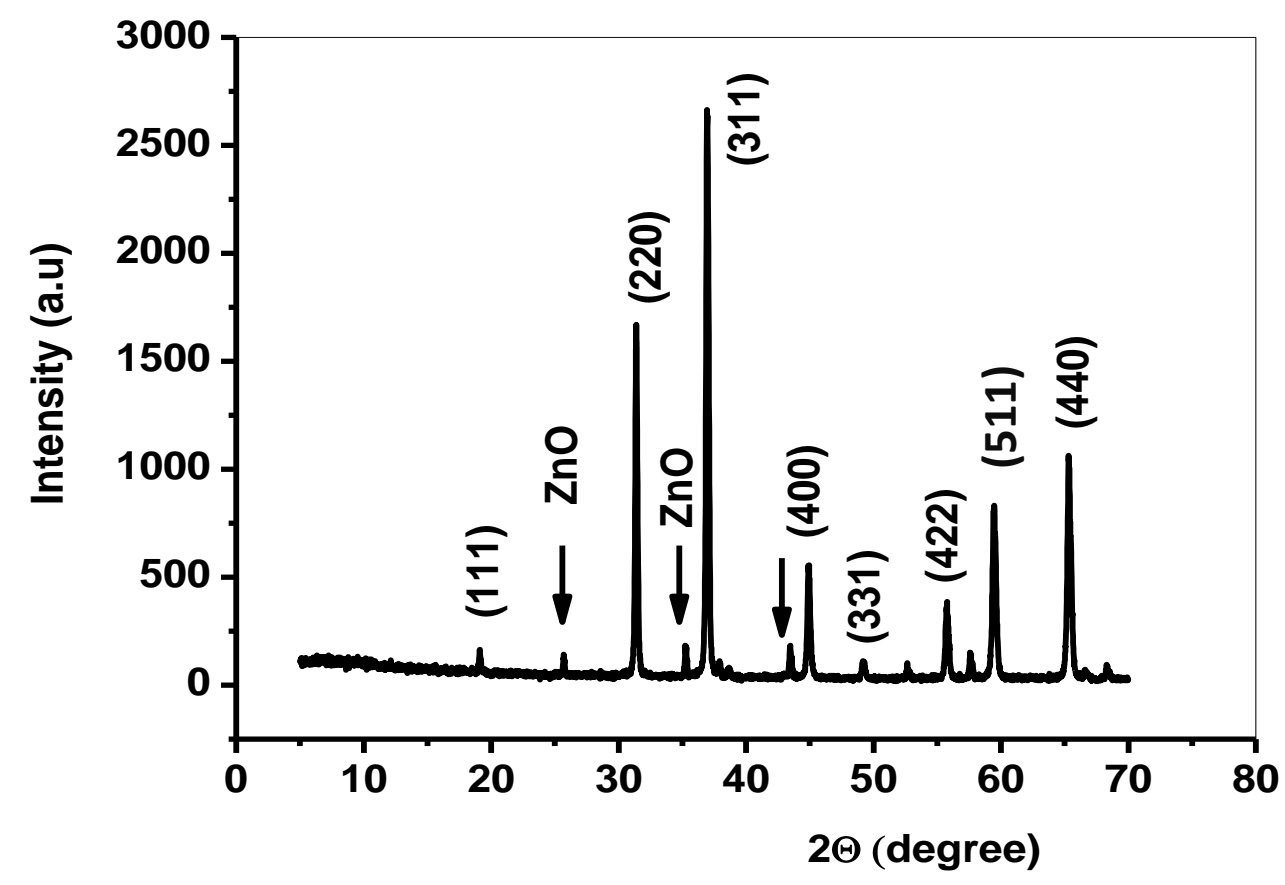

Fig. 1: X- Ray diffraction spectrum of $\mathrm{ZnAl}_{2} \mathrm{O}_{4}$ sample

The analysis of (X-Ray diffraction) explain that the main grains orientations of spinel formation found as (111), (220), (311), (400), (331), (422), (511) and (440) planes at $2 \theta$ values equal to $19.1^{\circ}, 31.4^{\circ}, 36.9^{\circ}, 44.9^{\circ}, 49.2^{\circ}, 55.8^{\circ}, 59.4^{\circ}$ and $65.5^{\circ}$ respectively. It also shows that there are traces and low percentages of zinc oxide $\mathrm{ZnO}$. These results are consistent with the results of other studies on the same article (Martin, 2010) (Ciupina, 2004).

The value of lattice constant $\left(a_{h k l}\right)$, a is calculated using Bragg's equation in the diffraction per peak of the spectrum (Cullity, 1978):

$$
\mathrm{a}_{(\mathrm{hkl})}=\frac{\lambda \sqrt{\mathrm{h}^{2}+\mathrm{k}^{2}+\mathrm{l}^{2}}}{2 \sin \theta_{(\mathrm{hkl})}}
$$

Table (1) shows that the values of $\left(a_{h k l}\right)$ for each set of detraction crystalline levels of Xrays. The average of these values is equal to $8.0573 \AA$. This value is very similar to other values obtained by other researchers and are equivalent to $8.086 \AA$ and $8.066 \AA$ (Gama, 2009). When 
compared with its counterpart in the natural spinel compound, Zinc Ferrite $\mathrm{ZnFe}_{2} \mathrm{O}_{4}$, which is equivalent to $8.4041 \AA$ (Suman, 2007) it is found to be less due to the difference between the radius of the iron ion $(0.67 \AA)$ and the radius of the aluminum ion $(0.54 \AA)$.

Table 1: The values of $\left(a_{h k l}\right)$ for each set of Diffraction crystalline planes of X-Rays

\begin{tabular}{|c|c|c|c|c|}
\hline $\mathbf{2 \theta}$ & $(\mathbf{h k l})$ & Intensity & $\operatorname{Sin} \boldsymbol{\theta}$ & $\boldsymbol{a}_{\boldsymbol{h} \boldsymbol{k} \boldsymbol{l}}(\AA)$ \\
\hline 19.1057 & 111 & 165 & 0.16587 & 8.0357 \\
\hline 31.3884 & 220 & 1669 & 0.27037 & 8.0507 \\
\hline 36.9366 & 311 & 2666 & 0.31663 & 8.0612 \\
\hline 44.9413 & 400 & 557 & 0.38320 & 8.0579 \\
\hline 49.1860 & 331 & 112 & 0.41597 & 8.0644 \\
\hline 55.7702 & 422 & 388 & 0.46748 & 8.0651 \\
\hline 59.4467 & 511 & 815 & 0.49558 & 8.0693 \\
\hline 65.4794 & 440 & 689 & 0.54058 & 8.0537 \\
\hline & & & Average & 8.0573 \\
\hline
\end{tabular}

The study also examined the measurement of Infrared spectrum of Zinc aluminate, $\mathrm{ZnAl}_{2} \mathrm{O}_{4}$ in the frequency range (400-1000 $\mathrm{cm}^{-1}$ ). Fig. (2) and (Table 2) show the infrared spectrum of the Zinc Aluminate $\mathrm{ZnAl}_{2} \mathrm{O}_{4}$ and shows that there are four frequencies with a clear Infrared absorption. They are at $(668,559,508,463) \mathrm{cm}^{-1}$ wave number [First frequency $v_{1}$ at $\left(668 \mathrm{~cm}^{-1}\right)$, second frequency $v_{2}$ at $\left(559 \mathrm{~cm}^{-1}\right)$, third frequency $v_{3}$ at $\left(508 \mathrm{~cm}^{-1}\right)$ and the fourth frequency $v_{4}$ at $\left(463 \mathrm{~cm}^{-1}\right)$ ]. (But the frequency $v_{0}$ at higher value than the other frequencies $\left(850 \mathrm{~cm}^{-1}\right)$ is due to the effects of the presence of traces the compound $\mathrm{ZnO}$ ) (Mineralogy Database, 2001-2005).

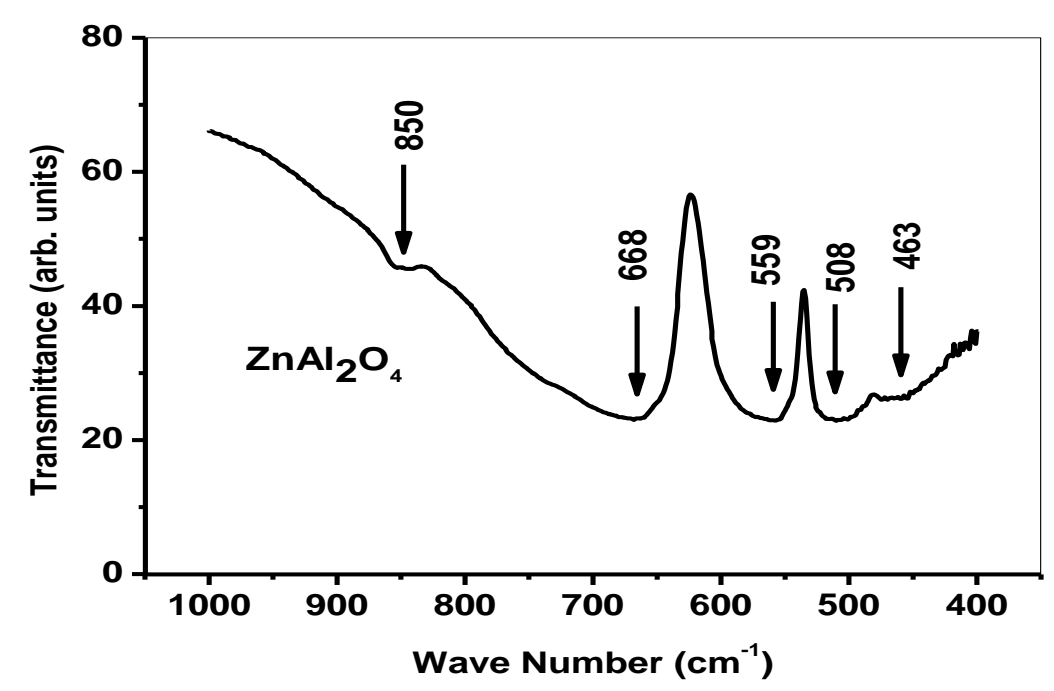

Fig. 2: IR spectrum of $\mathrm{ZnAl}_{2} \mathrm{O}_{4}$

Table 2: Values of the absorption frequencies of the Infrared the sample $\mathrm{Zn} \mathrm{Al}_{2} \mathrm{O}_{4}$

\begin{tabular}{|c|c|c|c|c|c|}
\hline Absorption Band & $\mathbf{Y}_{\mathbf{0}}$ & $\mathbf{Y}_{\mathbf{1}}$ & $\mathbf{Y}_{\mathbf{2}}$ & $\mathbf{Y}_{\mathbf{3}}$ & $\mathbf{Y}_{\mathbf{4}}$ \\
\hline Wave Number $\left(\mathbf{C m}^{-\mathbf{1}}\right)$ & 850 & 668 & 559 & 508 & 463 \\
\hline
\end{tabular}


Many studies on the spectrum of infrared absorption in spinel compounds have shown that they are due to:

First frequency $v_{1}$ : This frequency is primary and is due to the vibration of the divalent ion bonds (or triangular) with oxygen in the tetrahedral locations. Second frequency $v_{2}$ : This frequency is also major and is due to the vibration of three - valence bonds (or binary) with oxygen in octagonal locations. The third frequency $v_{3}$ is due to bi-metal vibrations with oxygen at eightsurface locations. The fourth frequency $v_{4}$ depends on the mass of the divalent ion vibration in the tetrahedral location (Modi, 2006).

The appearance of the first and second main frequencies is often cited as one of the main and important evidence of the complete spinel composition, the formation of the four-tiered subsystem and the eight-branch subsystem in the structure of the cell unit. The values of the first beam are higher than the values of the second beam, indicating that the bonds between the oxygen ions and the metal ions in the tetrahedral locations are shorter than those of the eight surfaces.

The main absorption frequency values can be used to calculate the average stress values of $\mathrm{K}_{\mathrm{t}}$ and $\mathrm{K}_{\mathrm{o}}$ between the ions in the tetrahedral and octahedral locations using the following relationships (Modi, 2006):

$$
\begin{aligned}
& \mathrm{K}_{\mathrm{t}}=7.62 \mathrm{M}_{1} \mathrm{v}_{1}^{2} 10^{-3}(\text { dyne } / \mathrm{cm}) \\
& \mathrm{K}_{\mathrm{o}}=5.31 \mathrm{M}_{2} \mathrm{v}_{2}{ }_{2} 10^{-3}(\text { dyne } / \mathrm{cm})
\end{aligned}
$$

Where $v_{1}, v_{2}, M_{1}$ and $M_{2}$ represent the absorption frequencies and the molecular mass rate in the tetrahedral and octahedral locations, respectively. The values of the molecular masses were calculated according to the distribution of ions between the sites mentioned on the basis that the aluminate of zinc is a natural spinel, that is, the distribution of cations takes the following formula:

$$
\left(\mathrm{Zn}_{1}^{+2}\right)^{\mathrm{A}}\left[\mathrm{Al}_{2}^{+3}\right]^{\mathrm{B}} \mathrm{O}_{4}^{-2}
$$

The brackets ()$^{\mathrm{A}}$ and []$^{\mathrm{B}}$ represent the positions of the tetrahedral and eight surfaces, respectively. The values of $\mathrm{M}_{1}, \mathrm{M}_{2}, \mathrm{~K}_{\mathrm{t}}$ and $\mathrm{K}_{\mathrm{o}}$ were equals to $65.926 \mathrm{~g} / \mathrm{mol}, 53.963 \mathrm{~g} / \mathrm{mol}$, $2.155 \times 10^{5}$ dyne $/ \mathrm{cm}$ and $0.8954 \times 10^{5}$ dyne $/ \mathrm{cm}$, respectively.

The information available from the $\mathrm{X}$-ray reflection can be used to calculate $\mathrm{D}_{\text {hkl }}$ the average size of the small crystalline space between plane of the compound using following equation (Cullity, 1978):

$$
\mathrm{D}_{\text {hkl }}=\frac{\mathrm{K} \lambda}{\beta_{\mathrm{hkl}} \cos \theta_{\text {hkl }}}
$$

Where $\mathrm{K}$ represents a fixed quantity and is often taken as equal to (0.9) and $\lambda$ represent the wavelength of X-ray used equal to $(1.5405 \AA)$, and $\beta_{\mathrm{hkl}}$, represents the maximum reflection width at maximum half values (FWHM; Full width at half maximum) at the angle, $\theta_{\mathrm{hkl}}$ and the rate of display of small crystals $D_{\text {hkl }}$. Using the main reflection of the X-ray diffraction spectrum (311) at the angle $2 \theta$ is equal to $\left(36.937^{\circ}\right)$ as shown in Fig. (3), we found the value of $D_{\text {hkl }}$ is equal to about $(41 \mathrm{~nm})$. A smaller size was obtained equal to $(34 \mathrm{~nm}),(11 \mathrm{~nm})$ (Ciupina, 2004) and (20 nm) (Gama, 2009) from samples prepared using different methods. It is known that the method of heat treatment in the preparation of samples often results in the size particles relatively large when compared with other preparation methods, because these samples show an increasing tendency for $\mathrm{Zn}$ to order into A sites to form a big normal spinels. (Henderson, 2007). 


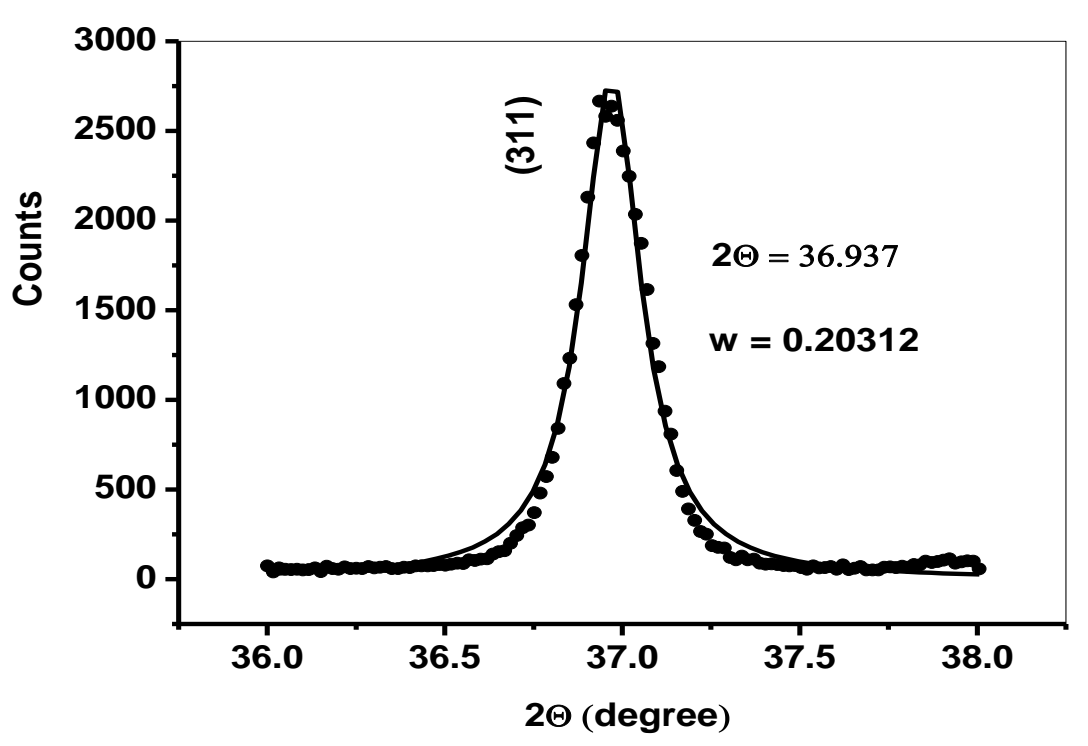

Fig. 3: The greatest diffraction of X-Ray in (311) direction

Beside the physical density can also be calculated the density XRD by using the following relation (Cullity, 1978):

$$
\rho_{\mathrm{XRD}}=\frac{8 \mathrm{M}}{\mathrm{N}_{\mathrm{A}} \mathrm{a}}
$$

Where $\mathrm{M}$ represents the molecular weight of the sample $(181.3403 \mathrm{~g} / \mathrm{mol}), \mathrm{N}_{\mathrm{A}}$ represents Avogadro's number $\left(6.02 \times 10^{23}\right)$ and $a_{(h k l)}$ is the measured lattice constant using X-Ray Diffraction data (8.0307 $\AA$ ). It was found that the theoretical density value equal to $4.653 \mathrm{~g} / \mathrm{cm}^{3}$.

The experimental density of material been used was calculated by finding a circular disk mass, the radius $r$ and thickness $t$ then applying the following equations:

$$
\begin{aligned}
& V=\pi r^{2} \mathrm{t} \\
& \rho_{E X P}=\frac{m}{V}
\end{aligned}
$$

It was found that the density value is equal to $1.876 \mathrm{~g} / \mathrm{cm}^{3}$. When comparing the densities, the theoretical density is higher than the practical density. This is due to the fact that the sample prepared in practice contains internal pores. Theoretically observed that band gap increase with the increase in the concentration of $\mathrm{Zn}$ suggests that the structural change occurring in the composite is responsible for such a variation (Joshi, 2003).

The porosity value, $\mathrm{P}_{\mathrm{o}}$ can be calculated by applying the following equation (Cullity, 1978):

$$
\mathrm{P}_{\mathrm{o}}=\left(\frac{\rho_{\mathrm{XRD}}-\rho_{\mathrm{EXP}}}{\rho_{\mathrm{XRD}}}\right) 100 \%
$$

It was found that the porosity value is equal to $60 \%$. This means that this sample contains component defects and it is porous as is the case with other type of components ferrite.

\section{CONCLUSIONS}

The main findings of this study can be summarized as follows:

1. Zinc aluminate $\mathrm{Zn} \mathrm{Al}_{2} \mathrm{O}_{4}$ was prepared using dual heat treatment method and high temperature.

$\mathrm{X}$-Ray measurements have shown that the quadrilateral spinel structure is positioned by the 
appearance of crystalline reflections on the structure. The cubic chain constant was calculated and found to be equal to $8.0573 \AA$.

2. The IR spectrum also showed the two main absorption bands, $v_{1}$ and $v_{2}$. The functions on the composition of the tetrahedral structure and the eight-brightness installation in the complete spinel structure. The value of $v_{1}$ equal to $685 \mathrm{~cm}^{-1}$, which was due to vibrations of the $\mathrm{Zn}^{2+}-$ $\mathrm{O}^{2-}$ bonds in the tetrahedral locations. While the value of $v_{2}$ equal to $569 \mathrm{~cm}^{-1}$ was attributed to the vibrations of the $\mathrm{Al}^{3+}-\mathrm{O}^{2-}$ bonds in octagonal locations. As well as other absorption frequencies.

3. The force parameters were calculated in the tetrahedral and octagonal sites using IR results and found to correspond to their values for this type of compound $\left(10^{5} \mathrm{dyne} / \mathrm{cm}\right)$.

4. The size of the small crystals in this compound was calculated by using the results of dental rays and found to be equal $(41 \mathrm{~nm})$. This value is considered a nature in this type of compounds and heat treatments.

5. The theoretical and practical densities of the sample and the porosity were calculated. These calculations showed that the sample contains structural defects and that it is porous with a large scale and about $60 \%$ as well as this type of compound.

\section{REFERENCES}

Ciupina, V.; Carazeeanu, I.; Prodan, G. (2004). Characterization of $\mathrm{ZnAl}_{2} \mathrm{O}_{4}$ nanocrystals prepared by coprecipitation and microemulsion techniques. J. Optoelect. Advanc. Mater., 6, $1317-$ 1322.

Cullity, B.D. (1978). Elements of X-ray Diffraction. Addison Wesley.

Gama, L.; Ribeiro, M.A.; Barros, B.S.; Kiminami, R.H.A.; Weber, I.T.; Costa, A.C.F.M. (2009). Synthesis and characterization of the $\mathrm{NiAl}_{2} \mathrm{O}_{4}, \mathrm{CoAl}_{2} \mathrm{O}_{4}$ and $\mathrm{ZnAl}_{2} \mathrm{O}_{4}$ spinels by the polymeric precursors method. J. Alloy. Comp. 483, $453-455$.

Henderson, C.M.B.; Charnock, J.M.; Plant, D.A. (2007). Cation occupancies in Mg, Co, Ni, Zn, Al Ferrite spinels: a multi-element EXAFS study. J. Phys. Condense. Matter., 19 (076214), 25.

Hill, R.J.; Craig, J.R.; Gibbs, G.V. (1979). Systematic of the spinel structure type. Phys. Chem. Miner. 4, 317-339.

Joshi, G.P.; Saxena, N.S.; Mangal, R.; Mishra, A.; Sharma, T.P. (2003). Band gap determination of $\mathrm{Ni}-\mathrm{Zn}$ ferrites. Bull. Mater. Sci., 26(4), 387-389.

Martin, R.F.; Serra, O.A. (2010). Thin film of $\mathrm{ZnAl}_{2} \mathrm{O}_{4}$ : $\mathrm{Eu}^{3+}$ synthesized by a non-alkoxide precursor sol-gel method. J. Braz. Chem. Soc., 21, 1395-1398.

Mineralogy Database, Mineral Data Publishing, version 1, (2001-2005).

Modi, K.B.; Trivedi, U.N.; Sharma, P.U.; Lakhani, V.K.; Chhantbar, M.C. (2006). Study of elastic properties of fine particles Copper-Zinc ferrites. Ind. J. Pure. Appl. Phys. 44, 165-168.

Sampath, S.K.; Kanhere, D.G.; Pandey, R. (1999). Electronic structure of spinel oxides: Zinc Aluminates and Zinc Gallate. J. Phys.: Condens. Matter., 11, 3635-3644.

Snelling, E.C. (1988). "Soft Ferrites: Properties and Applications". $2^{\text {nd }}$ ed. Butterworth-Heinemann.

Standley, K.J. (1962). "Oxide Magnetic Materials". Clarendon Press, Oxford.

Sugimoto, M.; Ceram, J. A. (1999). The past, present and future of ferrites. J. Phys. Condens. Matter., 82, 269-280.

Suman, R.L.; Sharma, N.D.; Taneja, S.P.; Reddy, V.R. (2007). Structural and magnetic properties of Zinc Ferrite Aluminates. Ind. J. Pure Appl. Phys., 45, 231-237. 